University of Nebraska - Lincoln

DigitalCommons@University of Nebraska - Lincoln

U.S. Environmental Protection Agency Papers

U.S. Environmental Protection Agency

2011

\title{
Embracing panarchy, building resilience and integrating adaptive management through a rebirth of the National Environmental Policy Act
}

\author{
Melinda Harm Benson \\ University of New Mexico - Main Campus, mhbenson@unm.edu \\ Ahjond S. Garmestani \\ United States Environmental Protection Agency, garmestani.ahjond@epa.gov
}

Follow this and additional works at: http:// digitalcommons.unl.edu/usepapapers

Benson, Melinda Harm and Garmestani, Ahjond S., "Embracing panarchy, building resilience and integrating adaptive management through a rebirth of the National Environmental Policy Act" (2011). U.S. Environmental Protection Agency Papers. 206.

http://digitalcommons.unl.edu/usepapapers/206

This Article is brought to you for free and open access by the U.S. Environmental Protection Agency at DigitalCommons@University of Nebraska -

Lincoln. It has been accepted for inclusion in U.S. Environmental Protection Agency Papers by an authorized administrator of

DigitalCommons@University of Nebraska - Lincoln. 


\title{
Embracing panarchy, building resilience and integrating adaptive management through a rebirth of the National Environmental Policy Act
}

\author{
Melinda Harm Benson ${ }^{a}$, Ahjond S. Garmestani ${ }^{\text {b,* }}$ \\ a Department of Geography, University of New Mexico, Bandelier Hall West Room 223, Albuquerque, NM 87131, USA

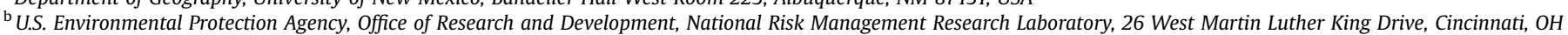 \\ 45268, USA
}

\section{A R T I C L E I N F O}

Article history:

Received 7 September 2010

Accepted 4 October 2010

Available online 20 October 2010

\section{Keywords:}

Law

Resilience

Adaptive management

Panarchy

NEPA

Sustainability

\begin{abstract}
A B S T R A C T
Environmental law plays a key role in shaping policy for sustainability of social-ecological systems. In particular, the types of legal instruments, institutions, and the response of law to the inherent variability in social-ecological systems are critical. Sustainability likely must occur via the institutions we have in place, combined with alterations in policy and regulation within the context of these institutions. This ecosystem management arrangement can be characterized as a panarchy, with research on sustainability specific to the scale of interest. In this manuscript we examine an opportunity for integrating these concepts through a regulatory rebirth of the National Environmental Policy Act (NEPA). NEPA currently requires federal agencies to take a "hard look" at the environmental consequences of proposed action. The original intent of NEPA, however, was more substantive and its provisions, while currently equilibrium based, may be reconfigured to embrace new understanding of the dynamics of social-ecological systems.
\end{abstract}

Published by Elsevier Ltd.

\section{Introduction}

The existing legal and regulatory framework for environmental protection in the United States has been remarkably successful at addressing many problems, particularly issues like water and air pollution that lend themselves to "command and control" regimes employed at the federal level. Unfortunately, these regimes have a limited capacity to address emerging "wicked problems" such as climate change and biodiversity loss, which are characterized by uncertainty (Ludwig, 2001; Norton, 2005). There are two main reasons why current approaches tend to be ineffective in this regard. First, current laws reflect assumptions of ecological equilibrium and stationarity that fail to acknowledge the complexity and unpredictability of natural systems (Glicksman, 2009; Craig, 2010). Second, the rigidity of our current legal structures makes it difficult to address cross-scale problems (Folke et al., 2007).

In order to meaningfully address the next generation of environmental challenges, we must reconfigure our legal and institutional frameworks. New approaches will need to have the flexibility necessary to incorporate both emerging theories regarding natural systems and new information gained by scientists and resource

\footnotetext{
* Corresponding author. Tel.: +1 (513) 569 7856; fax: +1 (513) 5697111.

E-mail addresses: mhbenson@unm.edu (M.H. Benson), garmestani.ahjond@epa. gov (A.S. Garmestani).
}

managers in the field. Here, we examine the systems theories of resilience and panarchy as important concepts that should be integrated into management efforts by resource agencies via adaptive management of natural resources. Second, we explain why current management regimes have difficulty embracing these concepts. Finally, we suggest one possible opportunity for integrating these emerging concepts through a regulatory rebirth of the National Environmental Policy Act (NEPA). NEPA currently requires federal agencies to take a "hard look" at the environmental consequences of proposed action. NEPA's original intent, however, was more substantive. Its provisions, while currently equilibrium based, may be reconfigured to embrace new theories and strategies regarding social-ecological systems.

\section{Emerging concepts in natural resource management}

\subsection{Resilience}

Resilience is the ability of a system to remain within a domain of attraction while exhibiting dynamic behavior (Folke et al., 2004). When a system is forced beyond the boundaries of a domain of attraction (i.e., a regime shift), a qualitatively different pattern of behavior may emerge. A regime shift can be dramatic or subtle, and the characteristics of the new regime will depend upon the feedback between the basin of attraction that characterizes the 
new regime and the driving variables in the system (Folke et al., 2004). While we have improved our understanding of resilience, there are challenges associated with measuring the resilience of a social-ecological system. However, we have gained a better understanding of system conditions that affect resilience. For instance, Daskalov et al. (2007), utilizing data from the Black Sea, detected two major regime shifts in the ecosystem. They attributed the first regime shift to a reduction in predators (e.g., pelagic predatory fish) and the second regime shift to an invasion by the non-indigenous comb jelly (Mnemiopsis leidyi) in the Black Sea. Daskalov et al. (2007) claim that the Black Sea regime shifts were driven by fishing pressure which resulted in systemic trophic cascades. For shallow lakes, the shift from an oligotrophic to a eutrophic regime can be preceded by an increase of the periphyton-layer covering the macrophytes and a reduction in the proportion of piscivorous fish (Brock et al., 2008). Regime shifts on many Caribbean coral reefs were preceded by loss of macro-fauna, declines in fish stocks, reduced coral recruitment, elevated destructive grazing by sea urchins (Diadema antillarum), as well as elevated nutrient and sediment influx from land (Bellwood et al., 2004). Each of these phenomena was well known, but the effect they individually had, or in combination, upon reef resilience was not foreseen (Bellwood et al., 2004).

The self-organization of systems into hierarchies generates resilience in dynamic systems (May et al., 2008). Strong interaction of components in complex systems (e.g., forest fires, epidemics) can lead to loss of resilience (May et al., 2008). Thus, almost all large systems should have hierarchical organization, and this is what we observe in nature (Simon, 1973). The cross-scale resilience model was developed in ecology as an improvement upon other models of biodiversity, and to describe hierarchy in ecological systems (Peterson et al., 1998). Numerous models of biodiversity have been proposed, but most fail to account for scale. In ecosystems, the diversity of functional groups across and within scales contributes to the resilience of the system (Folke et al., 2004). Functional diversity is an important aspect of resilience, but it must be coupled with functional redundancy to generate cross-scale resilience (Peterson et al., 1998). A functional group is a group of species that perform a similar ecological function (Bellwood et al., 2004). For example, Bellwood et al. (2004) identify three functional groups that are critical to coral reef resilience: (1) bioeroders (remove dead coral); (2) scrapers (remove algae) and (3) grazers (remove seaweed); without these critical functional groups, reefs are increasingly vulnerable to regime shifts.

Resilience is not only dependent upon the functional diversity of a system, but also dependent upon the range of responses (i.e., response diversity) within functional groups (Bellwood et al., 2004). The difference between functional redundancy and response diversity is that functional redundancy will be ineffective if every species of the same functional group interacts in the same manner (Bellwood et al., 2004). Thus, the value of high functional richness and redundancy is lost if redundant species do not "respond" differently to different stimuli (Bellwood et al., 2004). Further, response diversity is critical, as the interaction between species and stimuli is scale-dependent (Nystrom, 2006). The multiple but distinct scales of self-organization, and the distribution of function within and across scales, create resilient systems (Peterson, 1998). Thus, a system's resilience is dependent upon the interactions between structure and dynamics at multiple scales.

Our current understanding of resilience does not provide us with a "blueprint" that can be used without regard to scale-specific conditions (Garmestani et al., 2009). Since we cannot identify which species, functions or responses are "key" to ecological resilience, it is in humanity's best interests to preserve large regional species pools in heterogeneous locations, which will increase the chances that resilience, and therefore ecosystem services, will be maintained over time (Virah-Sawmy et al., 2009).

\subsection{Panarchy}

An adaptive cycle describes the processes of development and decay in a system (Gunderson and Holling, 2002). The initial stage of development of short duration consists of a rapid exploitation and garnering of resources by system components. This stage has been termed the $r$ stage or function. The $r$ stage is followed by a k stage or function, a stage of longer duration characterized by the accumulation of capital or other system elements or energies and increasing connectivity and rigidity. Increasing connectivity and rigidity during the $\mathrm{k}$ phase leads to decreased resilience and eventual collapse. This stage of collapse, the omega, is rapid and unleashes the "energy" accumulated and stored during the $\mathrm{k}$ phase. Collapse during the omega phase is followed by reorganization during the alpha phase, a relatively rapid period of assembly of components, analogous to the pioneer stage in ecosystems. A panarchy is a nested set of adaptive cycles (Gunderson and Holling, 2002).

For our purposes, panarchy is useful because environmental policy has often fallen into the "one-size fits all" trap that can lead to adverse policy outcomes, as there is no "best" scale for implementation of policy for linked social-ecological systems (Brock and Carpenter, 2007). Scale is the critical variable in monitoring and therefore policy associated with linked social-ecological systems. Cumulative impacts have the capacity to "scale up" in terms of their effect (Ruhl et al., 2007). As an illustration, large-scale destruction and degradation of wetlands, and the ecological services associated with those wetlands, has occurred primarily as a result of innumerable, small conversions of wetlands for agricultural and urban development; a tyranny of many small decisions (Ruhl et al., 2007). Within this context, no single conversion of a wetland appears to have much of an impact upon the delivery of ecosystem services (Ruhl et al., 2007). However, the cumulative impact of small-scale wetland transformations has produced large-scale degradation of the ecological services associated with those wetlands (Ruhl et al., 2007).

How does panarchy differ from hierarchy? Unlike the top-down control envisioned in traditional hierarchies, connectivity between adaptive cycles in a panarchy can be from levels above or below. In a hierarchy, lower-level patterns and processes are dominated by higher levels in the hierarchy. Panarchy differs from this characterization of nesting, with respect to complex systems, in that conditions can arise that trigger "bottom-up" (i.e., cross-scale cascading) change in the system (Garmestani et al., 2009). This model of social-ecological systems more accurately describes the "surprise" or uncertainty inherent in such systems. Further, levels in a panarchy are not static states, but rather adaptive cycles that are interconnected to other adaptive cycles in the panarchy. Each cycle operates over a discrete range of scale in both time and space and is connected to adjacent levels (adaptive cycles). It is important to note that adaptive cycles do not exist in isolation. Since adaptive cycles operate over specific ranges of scale, a system's resilience is dependent upon the interactions between structure and dynamics at multiple scales (Garmestani et al., 2009). With respect to the adaptive cycle, the critical variable is that change is the only constant. The trick is to embrace change and recognize that while change can be negative, from this process, new opportunities arise.

\subsection{Adaptive management}

Adaptive management is not a new environmental management strategy, but rather one that has not been fully explored and is underutilized. That partially stems from the difficulty associated with implementing an adaptive management program (Benson, 
2009). Adaptive management is an environmental management strategy that is an iterative process of decision-making and attempts to reduce the inherent uncertainty in ecological systems via constant system monitoring (Garmestani et al., 2009). C.S. 'Buzz' Holling and colleagues first developed the concept of adaptive management in the late 1970s in an attempt to incorporate the inevitability of scientific uncertainty into management actions involving natural systems (Holling, 1986). A central tenet of adaptive management is that management involves a continual learning process that should not be bifurcated into "research" and "regulatory activities" (Walters, 2002). In this sense, adaptive management represents a breakthrough in our thinking about natural resource challenges. Rather than providing discrete conclusions based on 'science,' it recognizes that our understanding of natural systems is constantly evolving (Benson, 2010a).

There are two types of adaptive management: passive and active (Garmestani et al., 2009). Passive adaptive management uses predictive models based upon current information to develop policy for the system of interest. The system is then monitored at a rate appropriate to the system of interest, and the results evaluated. From this information, models are improved and policies associated with the system are adapted to the new information. This differs from the familiar "trial and error" approach in which a policy likely to succeed is attempted and then abandoned in favor of a new approach when the first attempt fails (Karkkainen, 2005). Adaptive management is not simply responding to information with mitigation. Active adaptive management, which is generally regarded as superior to the more passive form (Walters, 2002), involves testing of multiple hypotheses about system management at the same time. Thus, in active adaptive management, policies are put "at risk" and learning is generated from successful and failed policies (Garmestani et al., 2009). Here we advocate for adaptive management, couched within the panarchy of ecosystems, institutions, and the legal framework of the United States, as a mechanism to facilitate improved environmental management (Garmestani et al., 2009).

\section{Integrating emerging conceptual understandings of natural systems into the law}

Institutional challenges are one of the greatest barriers for the implementation of adaptive management in ecological systems (Garmestani et al., 2009). There have been several efforts to integrate adaptive management strategies into existing federal legal and regulatory regimes in the United States. The U.S. Department of Interior's (DOI) Adaptive Management Working Group developed a technical guide for adaptive management implementation that has now been incorporated into the agency's departmental manual (Williams et al., 2007). The U.S. Forest Service is currently in the process of revising its planning rule and is soliciting feedback on how to successfully incorporate adaptive management (U.S. Forest Service, 2009). Prominent examples include the integration of adaptive management strategies within the context of landowner based habitat conservation planning under the Endangered Species Act (Ruhl, 2005a; Wilhere, 2009), and the compensatory wetlands mitigation protection program under the Clean Water Act (U.S. Army Corps, 2002).

All of these efforts reflect attempts to fit adaptive management within existing legal mandates and protocols. While existing management mandates are in many instances sufficiently vague to encompass adaptive management approaches, they do not provide a "regulatory home." As Professor J.B. Ruhl observed:

The disconnect between adaptive management in practice and adaptive management in law is quite palpable. Today's practitioner of natural resources law is bombarded with adaptive management. It is firmly entrenched in natural resource agency practice from headquarters to field level. It shows up in land management plans, resource development permits, and agency guidance documents. Yet, it appears almost nowhere as codified statutory or regulatory text, and it is dealt with significantly by only a handful of judicial opinions.... No other principle of natural resources law has so deeply permeated the practice on the basis of so little mention in law (Ruhl, 2008a).

From an implementation standpoint, the lack of a regulatory home is problematic. Without more specific statutory or regulatory grounding, commitments to adaptive management are generally not binding on the agency (Fischman, 2007). This means that those outside the agency are not able to enforce the agencies' commitment to adaptive management. Enforceability is important because, historically, judicial interpretation has been necessary to establish the details and define the duties and expectations of agency mandates and insure implementation (Nie, 2008). Without more specific and enforceable legal grounding, adaptive management principles are in danger of losing their legitimacy as "agency speak" with little meaning. Already, critics of adaptive management view it as an excuse to allow agencies an unreasonable amount of discretion (Doremus, 2002; Karkkainen, 2005; Houck, 2009a). In the same way, adaptive management proponents have cautioned against lax standards for adaptive management that would, in essence, create a situation in which agencies use it as "rhetorical cover for requests for blanket preauthorization to reverse or revise policies should the agency later decide to change its mind" (Karkkainen, 2004)(356).

\section{NEPA as a regulatory home}

The National Environmental Policy Act is in some ways the best known and most beloved environmental law in the United States. Passed by Congress in 1969 and signed into law in 1970, NEPA was enacted at a time of both unparalleled concern for the natural environment and optimism with regard to our capacity to address environmental challenges. NEPA's broad sweeping influence on environmental regulatory regimes in the United States prompted Karkkainen (2004) to observe that NEPA has "assumed quasiconstitutional status as one of the foundational laws of the modern administrative state."

NEPA boldly declared "national policy which will encourage productive and enjoyable harmony between man and his environment; to promote efforts which will prevent or eliminate damage to the environment and biosphere and stimulate the health and welfare of man; to enrich the understanding of the ecological systems and natural resources important to the Nation" (42 USC $\S$ 4321). Section 101 of NEPA declared that it was "the continuing policy of the Federal Government... to use all practicable means and measures, including financial and technical assistance, in a manner calculated to foster and promote the general welfare, to create and maintain conditions under which man and nature can exist in productive harmony, and fulfill the social, economic, and other requirements of present and future generations of Americans." This provision, sometimes referred to as the "substantive provision" of NEPA, was intended to require agencies to make not just well informed but also environmentally sound decisions balancing environmental and economic concerns (Caldwell, 2002). Kalen (in press) discusses in detail NEPA's legislative history which reveals that its enactment was a deliberate attempt to imbue agency decisionmaking and authority with what he calls the "rise in ecology". NEPA's original intent was to have the federal government's decisions reflect this new thinking and bring it to bear on agency actions.

But NEPA's bold intentions got lost along the way. Its substantive goal never came to fruition because it was quickly undermined by 
court interpretations of the law, which held that NEPA's Section 101 was an aspirational statement lacking the necessary detail for enforcement. In the U.S. Supreme Court decision Stryker's Bay Neighborhood Council, Inc. v. Karlen, the Court held that NEPA, while establishing "significant substantive goals for the Nation, imposes upon agencies duties that are essentially procedural. ... NEPA was designed to insure a fully informed and well-considered decision" (1980). As a result of these court interpretations, NEPA essentially became a series of procedural steps requiring federal agencies to take a "hard look" at the potential environmental consequences of their actions, but not requiring them to take any specific action to protect the environment or balance competing concerns (Kalen, 2009 , in press).

Consequently, the focus for NEPA implementation is currently Section 102, which requires agencies to provide a "detailed statement" (known as an "Environmental Impact Statement" or "EIS") outlining the environmental impacts of the proposed action (Fig. 1). First, the agency determines whether the proposed action will have a major impact on the environment. If the answer is yes, the agency proceeds with a "scoping" phase during which it outlines the basic details of the proposed action and solicits public comment. It then issues a Draft Environmental Impact Statement (DEIS) for further review by the public. The DEIS analyzes the potential environmental impacts of the proposed action, lists alternatives to the action, and explains whether the action involves any "irretrievable or irreversible" commitments of resources by the agency. It also assesses any cumulative impacts from the action in relation to other relevant projects and proposals by the agency. Once the public input is considered, a final EIS is issued, followed by a Record of Decision that outlined the agency's decision. If the agency is unsure whether its proposed action is "significant," or whether (as will be discussed below) it concludes that the environmental impacts, while significant, have already been assessed in a previous NEPA analysis, it may conduct a less onerous Environmental Assessment (EA) to determine whether an EIS is required. If the answer is "yes," the agency proceeds with the EIS procedure outlined above. If the answer is "no" the agency issues a "Finding of No Significant Impact" (FONSI) briefly explaining why an EIS is not required. These procedural steps fulfill what is often termed the "twin aims" of NEPA: (1) providing better informed agency decisions and (2) involving the public in decision-making (1983).

NEPA's original intent was to accomplish much more than a set of procedural steps and a "hard look" at the impact of federal actions on the environment. NEPA's substantive provision has embedded

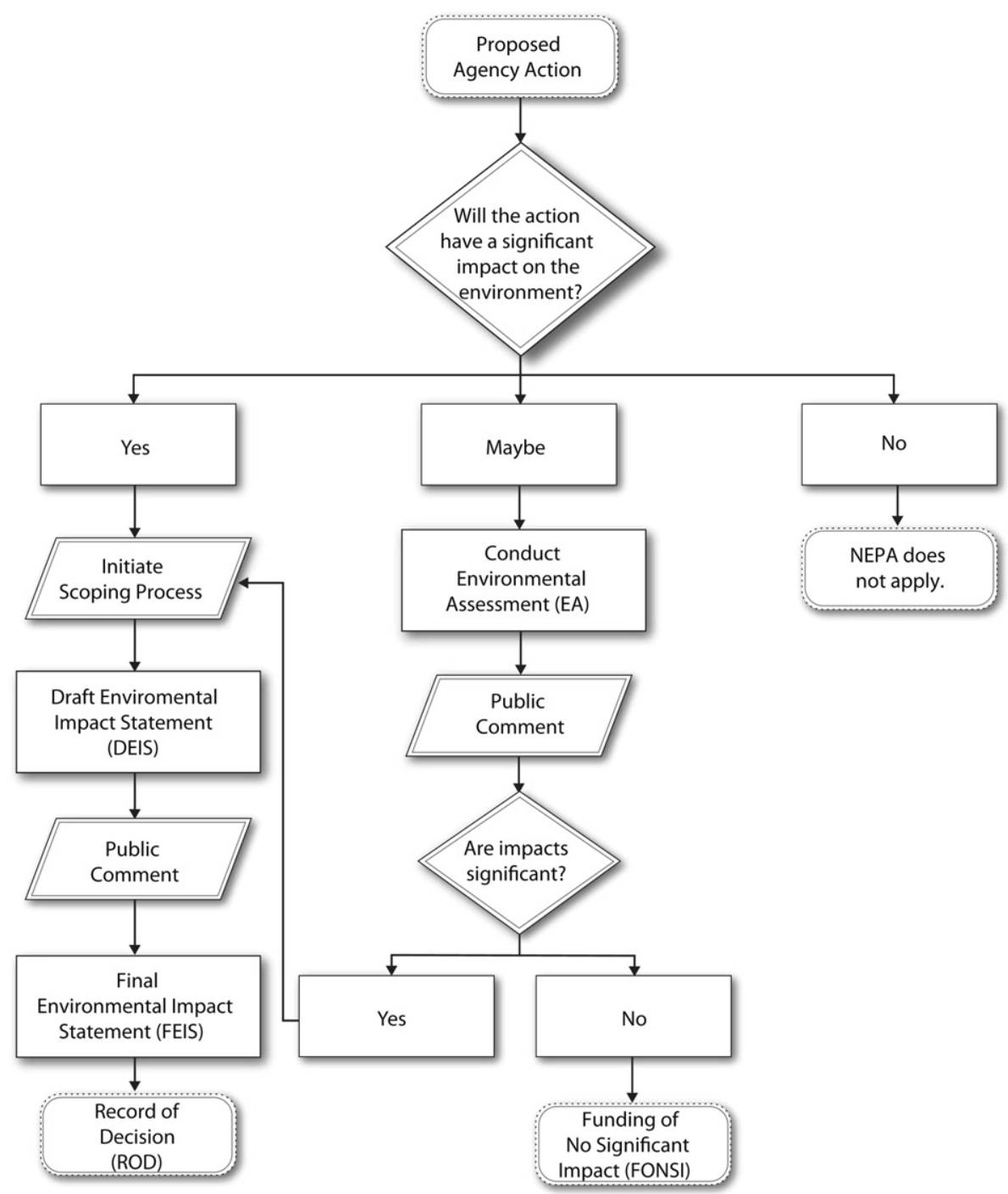

Fig. 1. A flowchart of a typical NEPA decision-making process, characterized by front end and linear processes. 
within it concepts of sustainability and ecological integrity. Integrating adaptive management into NEPA's requirements may provide a way to reclaim NEPA's potential while also securing it the necessary regulatory home for adaptive management. Incorporation of adaptive management into NEPA also has the potential to allow agencies to "manage for resilience". Reclamation of NEPA's potential through integration of adaptive management principles would be particularly fitting given that it was actually the frustration associated with similar environmental assessment processes that prompted C.S. Holling and his colleagues to develop adaptive management in the first place (Karkkainen, 2005). The frustration arose from environmental assessment procedures like NEPA that reflect a "front end approach" that assume that resource managers possess (1) a serviceable knowledge of natural systems and (2) the capacity to predict the environmental impact of a proposed action before any activity occurs (Ruhl, 2005a; Thrower, 2006). These procedural processes place ecologists, conservation biologists and others informing management processes in an untenable position. It was precisely this disconnect-the conceptual chasm between this expectation of perfect knowledge and the reality that only a fraction of the information needed to make such an assessment was readily available - that gave birth to adaptive management as a vehicle for "learning by doing" (Holling, 1986; Walters and Holling, 1990).

There are several advantages to NEPA, if reconfigured in the manner described below, which might make it a good regulatory home for adaptive management. First, NEPA already requires all federal agencies to conduct complex, often multiscalar environmental assessments of proposed activities. This stands in contrast to most other federal environmental laws, which focus on specific media (air, water, etc.) or on regulating private entities through "command and control" permitting processes (Craig, 2010). NEPA analyses often deal with addressing cross-scale challenges associated with multiple human systems and jurisdictions. NEPA's history with overlapping environmental challenges, including their cumulative impacts and their implications for regulation and permitting decisions that impact private entities, makes it a good candidate for an approach that embraces panarchy. Next, NEPA's public participation requirements provide a vehicle for situating the stakeholderbased, collaborative processes necessary for effective management of public resources (Keough and Blahna, 2006). Agencies implementing NEPA already have significant experience working with multiple, often disparate interests in this context, providing a good basis for further implementing a more formalized role for various stakeholders, including local communities, members of industry, and conservation groups. Finally, the fact that NEPA applies to all "major federal actions" that have a significant impact on the human environment allows for more uniform application across federal agencies. This would enhance social learning among practitioners as they engage adaptive management methodologies. More consistent integration of adaptive management principles into NEPA would provide important depth and consistency to both agency and court interpretations of adaptive management.

We are not the first to suggest further integration of adaptive management within NEPA. In 2002, the Council on Environmental Quality (CEQ), the agency responsible for overseeing NEPA implementation, created a NEPA Taskforce to address issues associated with modernizing NEPA, including the need for better integration of adaptive management (Karkkainen, 2004). A year later, the NEPA Taskforce did come forward with a series of recommendations, which included the recommendation that the CEQ promulgate regulations specific to adaptive management, but this has not yet happened (Benson, 2010a). Instead, resource agencies are developing adaptive management guidelines of their own. For example, the Department of Interior recently stated that in implementing NEPA its bureaus "should use adaptive management, as appropriate, particularly in circumstances where long-term impacts may be uncertain and future monitoring will be needed to make adjustments in subsequent implementation decisions." (43 C.F.R. $\S 46.145$ ). When using adaptive management, the regulations state that the NEPA analysis should identify the range of management options that may be taken in response to the results of monitoring and should analyze the effects of such options. It also required that the environmental effects of any adaptive management strategy be evaluated in subsequent NEPA analysis.

While these efforts are laudable, they are not sufficient to effectively integrate adaptive management, for two reasons. First, they still reflect an approach based on linear rather than iterative processes. By working within NEPA's existing framework, these guidelines do not accomplish the necessary feedback loops required for adaptive management. Under the current regime, the "subsequent NEPA analysis" referred to by the regulation is only triggered in limited circumstances, such as when significant new information triggers a new EIS or the agency proposes a new major federal action. Second, because NEPA's current mandate is procedural rather than substantive, the current regulatory implementation of adaptive management also lacks the substance and structure needed for effective implementation. We argue here that more fundamental reform of NEPA is needed to make adaptive management an actual requirement.

\subsection{Reconfiguration of NEPA}

If NEPA were to be reconfigured to integrate adaptive management and account for ecological resilience, several specific reforms are necessary. First, and foremost, NEPA's "front end" approach needs to be reworked in order to reflect the iterative processes required by adaptive management. As a practical matter, many agencies are already taking steps in this direction and are increasingly using a process called "tiering". Tiering allows agencies to sequence NEPA documents, starting with broad "programmatic" EISs that address larger policy issues and/or the initial stages of a program or project and then supplementing programmatic documents with more site-specific analyses (Fig. 2). A programmatic EIS generally provides a suite of both environmental analyses and authorizations for site-specific projects and allows agencies to examine impacts at the landscape level. The DOI's current approach to oil and gas development provides one example (Benson, 2009). A programmatic EIS authorizing leasing decisions is made initially at the planning stage, and then project level EISs accompany the location and development of a particular area. Site-specific EAs that

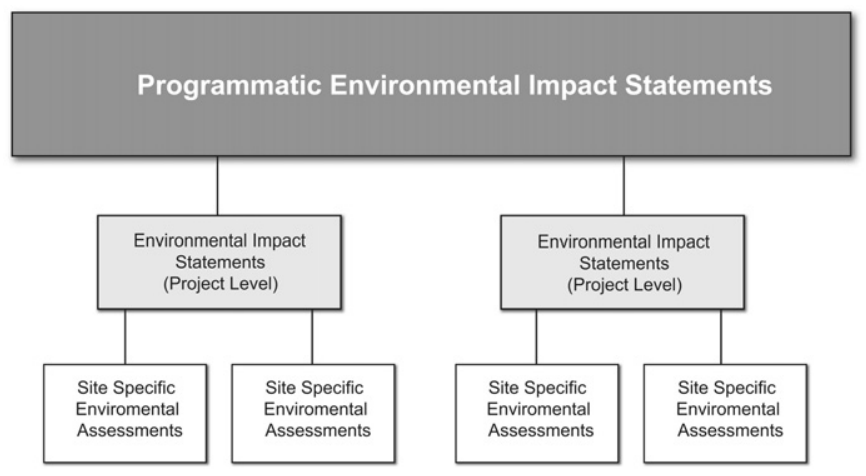

Fig. 2. A schematic of NEPA depicting tiering, which allows agencies to sequence NEPA documents, starting with broad programmatic EISs that address larger policy issues and initial authorizations, and form the basis for more refined NEPA analyses. 
address actual drilling then apply the project level EIS analysis to activities on the ground (Benson, 2009).

The current regulatory guidance specifically encourages tiering in situations where decision-making occurs in stages (40 Code Federal Regulations $\S 1502.20)$. The regulations also anticipate situations in which there is incomplete or unavailable information. In situations where it is impractical to obtain the needed information, the regulations direct the agency to both (1) provide a "statement that such information is incomplete or unavailable" and (2) include a "statement of the relevance of the incomplete or unavailable information to evaluating reasonably foreseeable significant adverse impacts on the human environment" along with a summary of the "credible scientific evidence which is relevant" (40 Code Federal Regulations $\S 1502.22$ ).

Adaptive management would incorporate both approaches, building the informational needs into the conceptual model and designing management approaches that would begin to fill in the gaps and guide future action. As can be seen by this brief overview, current regulations already provide some basis for working with uncertainty, but full integration of adaptive management's iterative approach and embracing panarchy would require development of specific protocols to guide implementation and shift from a linear model to an iterative process that allows site-specific action to inform larger programmatic goals. An iterative NEPA process, as outlined in Fig. 3, would mimic an adaptive cycle. This iterative process would begin at the $r$ stage or function; this stage of the adaptive cycle would be associated with the landscape scale, programmatic NEPA analysis, usually at a planning stage. This organization of system elements - the basis for the management obligations and goals-is characterized both by intentional connectivity of multiple proposed management actions and relative rigidity in terms of legal obligations and protocols. This forms the basis for project-based environmental impact statements, which are captured in the K stage of the adaptive cycle. However, rather than decreased resilience and eventual collapse in the classic adaptive cycle, as the cycle proceeds to the $\Omega$ stage, the project stage incorporates iterative processes in order to bridge the planning and action stages, unleashing both the management goals and accounting for ecological uncertainty (now explicitly organized as assumptions built into management protocols). The $\Omega$ stage consists of on the ground, site-specific activities (e.g., environmental assessments). These functions then feedback into the $\alpha$ phase and form the basis for reorganization, integration of knowledge and further realignment of the human with the natural system based on the monitoring and assessment of data.

This model shifts NEPA's processes from a linear model to an iterative process better suited to the panarchy of ecological systems. Similarly it moves the theoretical advancements of

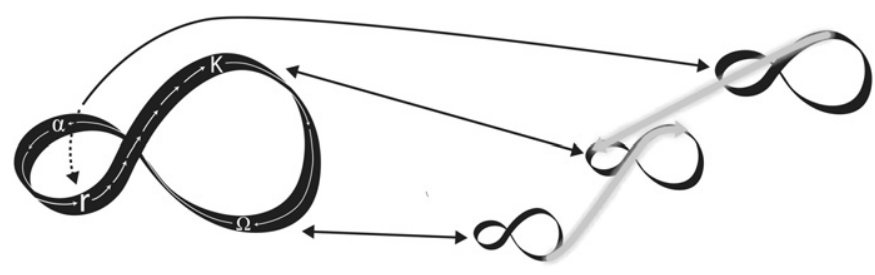

Fig. 3. The adaptive cycle on the left depicts an iterative NEPA process in which landscape scale planning (project impact analysis) would be associated with the $r$ stage, the project scale (environmental impact analysis) would be associated with the $\mathrm{K}$ stage, and site-specific actions (environmental assessments) would be associated with the $\Omega$ stage. For the panarchy of ecological systems on the right (i.e., nested set of adaptive cycles), the large ecological scales would be associated with the $r$ stage, medium ecological scales would be associated with the K stage, and small scales would be associated with the $\Omega$ stage. Adapted from Gunderson and Holling (2002). panarchy and resilience into practical consideration by agencies. In this iterative NEPA process, large ecological scales would be associated with the $r$ stage, medium ecological scales would be associated with the $\mathrm{K}$ stage, and small scales would be associated with the $\Omega$ stage (Fig. 3). Taking the oil and gas development example used previously, a landscape scale examination of the social-ecological challenges associated with energy development on federal lands would not only include the development and identification of management objectives regarding the "reasonably foreseeable development scenarios" for oil and gas leasing but would also include the development of a conceptual model that explicitly incorporated the uncertainties associated with unknown impacts to wildlife, the location of transmission corridors, etc. The plan would guide the authorization of project level development, would refine the model to address the needs of a particular location and also identify how the project might inform the conceptual model while also meeting management objectives. Site-specific actions (in this case the drilling of actual wells) identified at the project level would then provide the basis for experimentation and learning. The information gained at the sitespecific level (for example, the impact of a particular hydraulic fracturing method on groundwater quality) could be used to guide both further actions under the project and future planning at the landscape scale. This is different from the current linear approach, even those that attempt to incorporate adaptive management, because it would shift away from a rigid "record of decision" at the planning stage that cannot be reorganized until a plan is formally revised or amended. The landscape scale planning under an iterative NEPA process would preserve the capacity to adapt. Importantly, this would require a willingness to move forward with project level actions at both a spatial and temporal scale that would allow for learning.

The second, closely related, major reform needed to reconfigure NEPA to accommodate adaptive management is to require monitoring (Moir and Block, 2001). Monitoring is an essential component of adaptive management. A monitoring program that is designed to assess management experiments is necessary to provide the feedback allowing for further knowledge integration and iteration. The DOI's guidance specifically emphasizes this point: "Monitoring is used in adaptive management to track system behavior, and in particular to track the responses to management through time. In the context of adaptive management, monitoring is seen as an ongoing activity, producing data after each management intervention to evaluate the intervention, update the measures of model confidence, and prioritize management options in the next time period (U.S. Department of Interior, 2008) (33)." Currently, NEPA's regulations state that "[a]gencies may provide for monitoring to assure that their decisions are carried out and should do so in important cases." It falls short of actually requiring monitoring (with one exception noted below) and monitoring, as a practical matter, is often abandoned when budgets require agencies to cut back on operations (Benson, 2009). NEPA has the potential to provide the legislative mandate for monitoring, which would allow agencies to build the necessary funding into their budgets and, when appropriate, require financial support from those seeking to develop resources on public lands.

The third key element of NEPA reform needed to achieve adaptive management is an affirmative obligation to engage in mitigation of environmental impacts. NEPA is triggered when there is a proposed action that will have a major impact on the environment. Reviving NEPA's substantive provision, which includes an affirmative obligation to address environmental concerns rather than just take a procedural "hard look" will require the mitigation of environmental impacts. Mitigation is currently defined by the NEPA regulations to include: (a) Avoiding the impact altogether by not taking a certain action or parts of an action. (b) Minimizing 
impacts by limiting the degree or magnitude of the action and its implementation. (c) Rectifying the impact by repairing, rehabilitating, or restoring the affected environment. (d) Reducing or eliminating the impact over time by preservation and maintenance operations during the life of the action. (e) Compensating for the impact by replacing or providing substitute resources or environments (40. C.F.R \$1508.20). While NEPA currently requires an examination of "appropriate mitigation measures not already included in the proposed action or alternatives" it does not generally require their implementation (40 C.F.R $\S 1502.14(\mathrm{f})$ ). To the extent to which mitigation has been encouraged under NEPA, it has been done indirectly by agencies seeking to avoid NEPA requirements by developing mitigated "findings of no significant impact" or "FONSIs" that allow them to avoid the requirements of an EIS (Karkkainen, 2004; Haugrud, 2009). Where the NEPA process does end up choosing an alternative requiring mitigation, NEPA requires the agency to also conduct monitoring (the exception noted above) and allows the agency to condition its approval of permits, funding and other activities on the mitigation required by the decision. NEPA falls short of consistently requiring mitigation. A revitalized NEPA would combine both monitoring and mitigation to achieve the substantive goals that were NEPA's original intent.

The final reform necessary is to insert NEPA back into agency planning. Just as early cases eviscerated NEPA's substantive provision early on, court decisions also narrowly defined "agency action," exempting many planning processes (Houck, 2009b; Mandelker, 2009) This has long been regarded as one of the major failings of NEPA implementation, leaving the "hard look" for individual actions, and therefore missing the opportunity to decide whether to engage in a proposed action at the more forward looking and comprehensive planning stage. Adaptive management requires agencies to use planning as an opportunity to develop a conceptual model and management objectives to guide agency decisions and then integrate new information back into management frameworks. NEPA at the planning stage, as integrated toward a more iterative process, is a common sense reform necessary to meet NEPA's original intent and is vitally necessary to the programmatic cycle.

\section{Observations, limitations, and conclusions}

All of these reforms-integration of an iterative process, requiring monitoring and mitigation, and reinserting NEPA's "hard look" at the planning stage-have the potential to make adaptive management possible, which in turn would allow for managers to embrace panarchy and build resilience in social-ecological systems. If implemented, these reforms would provide agencies with the necessary flexibility to more meaningfully address the many wicked problems they now face. There are, of course, limitations to such an approach. Like most statutes of its era, NEPA has embedded within it the concept of ecological equilibrium (Thrower, 2006). In its current form, NEPA's requirements reflect these assumptions. However, the reconfiguration outlined in this manuscript would allow for a shift in the regulatory framework away from the focus on a single "agency action" designed to achieve "productive harmony" to a suite of ongoing activities that are monitored and adjusted as necessary to achieve management goals. This is consistent with the substantive goals of NEPA, which are based on the underlying principles of sustainable use and ecological integrity.

Perhaps a more significant obstacle is the fact that administrative law regimes assume there is a "final agency action" that allows for judicial review (Ruhl, 2005b). This core assumption of finality, which was designed to accommodate linear rather than iterative processes, has been identified as a fundamental impediment to adaptive management (Ruhl, 2005b, 2008a,b). As a possible solution Karkkainen (2005) has recommended the creation of an "adaptive management track", where a new set of administrative law standards specific to adaptive management would hold precedence. Shifting our human systems (in this case agency decision-making) to the iterative processes that reflect and mimic the panarchy of natural systems may be required beyond NEPA in order to facilitate enforceability. As emphasized earlier, the current unenforceability of existing integrations of adaptive management within current management regimes threatens the integrity of the adaptive management approach. An iterative process will need to be held accountable through enforceable mechanisms in administrative law.

Reform of NEPA in this way would in effect reform the resource management mandates of all federal agencies. At the moment, NEPA is simply a procedural hurdle for agencies; it does not require federal agencies to adjust their decisions and outcomes to accommodate environmental concerns but instead tells them to take a "hard look" at the environmental impacts for proposed actions. Embracing NEPA's substantive provision by requiring agencies to engage in monitoring and mitigation of environmental impacts would place NEPA squarely as the gatekeeper of environmental protection and sustainability it was intended to be. While some might argue that this would only be viable to the extent NEPA's requirements are consistent with existing management mandates of natural resource agencies (Craig, Personal communication), it is possible to place substantive mandates on federal agencies beyond their primary obligations under their enabling statutes. The Endangered Species Act, for example, requires federal agencies to avoid jeopardizing endangered species, regardless of their other regulatory obligations (Benson, 2010b). While it is true that adherence to NEPA's substantive mandate may create even more tension than ESA compliance has for many federal agencies, adaptive management itself provides the tools necessary for the recognition of these tensions and strategies for addressing them. To the extent they cannot be reconciled, the tension may highlight the need for shifts in current agency priorities and mandates to reflect contemporary natural resource challenges.

Admittedly, there may be challenges associated with such a drastic reconfiguration of an existing law. Many familiar with NEPA's current, procedural approach might balk at the reclamation of NEPA's substantive potential. While the shift would be dramatic, it is possible that reconfiguration of NEPA could be achieved without new legislation or congressional amendment. The CEQ, in its role as the main interpreter of NEPA, could implement new regulations requiring adaptive management for agency actions that trigger NEPA and could outline specific protocols and methodologies to implement adaptive management. To date, the CEQ has never attempted to exercise its authority it this manner. The CEQ's own regulations state that "The President, the federal agencies, and the courts share responsibility for enforcing the Act so as to achieve the substantive requirements of section 101." (40 C.F.R. 1500.1). This implies that the CEQ has this authority.

Kalen (in press) notes that, while such a substantive reform of NEPA would be a significant statutory reinterpretation, it would be permissible under general principles of administrative law because, as noted above, NEPA's original intent was to play a more substantive role in agency decision-making. He argues that "the Supreme Court's crabbed interpretation of NEPA should be susceptible to modification by CEQ guidance" citing a recent U.S. Supreme Court decision (2005), which held that federal agencies can adopt new regulations that reinterpret a statutory provision previously defined by the courts under certain circumstances (Kalen, in press). Those circumstances include when the court's interpretation was not held by the court as "the only reasonable" interpretation of the statute. In the case of NEPA, none of the early interpretations of its requirements were based on a "clear reading" of the statutory language. To the contrary, the courts ignored the substantive statutory language in Section 101 and instead focused on the procedural requirements 
outlined in Section 102. Despite previous court decisions, NEPA can be reinvigorated without statutory amendment. Given that Congress has generally proven reluctant to pass new environmental legislation over the past several decades, achievement of sustainability could most easily occur via the institutions we have in place, combined with alterations in policy and regulation within the context of these institutions. For this reason, there are distinct advantages to using NEPA as an existing legal requirement, rather than waiting for a new statutory framework.

Further, panarchy is a useful model for characterizing ecological systems and the formal institutions that manage these systems, and therefore actualizing ecosystem management (Garmestani et al., 2009). Institutional challenges are one of the greatest barriers for building resilience in ecological systems (Lant et al., 2008; Garmestani et al., 2009). The key is facilitating crossscale communication across the panarchy of institutions and ecosystems, with explicit recognition of the underlying cross-scale structure and processes of these linked systems. The linear nature of the current NEPA process illuminates that iterative mechanisms are needed to catalyze the effective management of natural resources at multiple scales (Garmestani et al., 2009). Since a degree of uncertainty is inherent in social-ecological systems, the generation of adaptive capacity in management entities is a necessary "insurance policy" for sustainability (Gunderson, 1999). Adaptive capacity in social-ecological systems is characterized by open and frequent lines of communication between institutions at multiple scales. A reconfiguration of NEPA from a linear to an adaptive process has the potential to revive NEPA's substantive provisions while also providing a much needed regulatory home for adaptive management and emerging understanding of the dynamics of social-ecological systems.

\section{Acknowledgements}

This manuscript was improved thanks to comments from Sam Kalen and J.B. Ruhl, and two anonymous reviewers.

\section{References}

Baltimore Gas \& Elec. Co. v. Natural Resources Defense Council. (1983). U.S. Supreme Court.

Bellwood, D.R., Hughes, T.P., Folke, C., Nystrom, M., 2004. Confronting the coral reef crisis. Nature 429, 827-833.

Benson, M.H., 2009. Integrating adaptive management and oil and gas development: existing obstacles and opportunities for reform. Environmental Law Reporter 39, 10962-10978.

Benson, M.H., 2010a. Adaptive management approaches by resource management agencies in the United States: implications for energy development in the interior west. Journal of Energy and Natural Resources Law 28, 87-118.

Benson, M.H., 2010b. Legislative reallocation: how compliance with federal legislative initiatives can redistribute water resources. Journal of Contemporary Water Resources Research 144, 1-7.

Brock, W.A., Carpenter, S.R., 2007. Panaceas and diversification of environmental policy. Proceedings of National Academy of Sciences 104, 15206-15211.

Brock, W.A., Carpenter, S.R., Scheffer, M., 2008. Regime shifts, environmental signals, uncertainty, and policy choice. In: Norberg, J., Cumming, G.C. (Eds.), Complexity Theory for a Sustainable Future. Columbia University Press, New York, pp. 180-206.

Caldwell, L.K., 2002. The National Environmental Policy Act: Judicial Misconstruction, Legislative Indifference, \& Executive Neglect. Texas A\&M University Press, College Station.

Craig, R.K., 2010. Stationarity is dead: long live transformation: five principles for climate change adaptation law. Harvard Environmental Law Review 34, 9-74.

Daskalov, G.M., Grishin, A.N., Rodionov, S., Mihneva, V., 2007. Trophic cascades triggered by overfishing reveal possible mechanisms of ecosystem regime shifts. Proceedings of the National Academy of Sciences 104, 10518-10523.

Doremus, H.A., 2002. Adaptive management, the Endangered Species Act, and the institutional challenges of "new age" of environmental protection. Washburn Law Journal 41, 50-89.

Fischman, R.L., 2007. From words to action: the impact and legal status of the 2006 National Refuge System Management Policies. Stanford Environmental Law Journal 26, 77-135.
Folke, C., Carpenter, S., Walker, B., Scheffer, M., Elmqvist, T., Gunderson, L., Holling, C.S., 2004. Regime shifts, resilience, and biodiversity in ecosystem management. Annual Review of Ecology, Evolution, and Systematics 35, 557-581.

Folke, C., Pritchard, L., Berkes, F., Colding, J., Svedin, U., 2007. The problem of fit between ecosystems and institutions: ten years later. Ecology and Society 12 (1), 30. http://www.ecologyandsociety.org/vol12/iss1/art30/.

Garmestani, A.S., Allen, C.R., Cabezas, H., 2009. Panarchy, adaptive management and governance: policy options for building resilience. Nebraska Law Review 87, 1036-1054.

Glicksman, R.L., 2009. Ecosystem resilience to disruptions linked to global climate change: an adaptive approach to federal land management. Nebraska Law Review 87, 835-891.

Gunderson, L., Holling, C.S., 2002. Panarchy: Understanding Transformations in Human and Natural Systems. Island Press, Washington, D.C.

Gunderson, L.H., 1999. Stepping back: assessing for understanding in complex regional systems. In: Johnson, K.N., Swanson, F., Herring, M., Greene, S. (Eds.), Bioregional Assessments: Science at the Crossroads of Management and Policy. Island Press, Washington, D.C., pp. 27-40.

Haugrud, J.K., 2009. Perspectives on NEPA: let's bring a bit of substance to NEPA making mitigation mandatory. Environmental Law Reporter 39, 10638-10639.

Holling, C.S., 1986. Adaptive environmental management. Environment 28, 39.

Houck, O.A., 2009a. Nature or nurture: what's wrong and what's right with adaptive management. Environmental Law Reporter 39.

Houck, O.A., 2009b. How'd we get divorced?: the curious case of NEPA and planning. Environmental Law Reporter 39, 10645-10650.

Kalen, S., 2009. The devolution of NEPA: how the APA transformed the nation's environmental policy. William and Mary Law Environmental Law Review 33, 483-548.

Kalen, S. Ecology comes of age: NEPA's lost mandate. Duke Environmental Law \& Policy Forum, in press.

Karkkainen, B.C., 2004. Whither NEPA? New York University Environmental Law Journal 12, 333-363.

Karkkainen, B.C., 2005. Panarchy and adaptive change: around the loop and back again. Minnesota Journal of Law, Science and Technology 7, 59-77.

Keough, H.L., Blahna, D.J., 2006. Achieving integrative, collaborative ecosystem management. Conservation Biology 20, 1373-1382.

Lant, C.L., Ruhl, J.B., Kraft, S.E., 2008. The tragedy of ecosystem services. Bioscience 58, 969-974.

Ludwig, D., 2001. The era of management is over. Ecosystems 4, 758-764.

Mandelker, D., 2009. Thoughts on NEPA at 40. Environmental Law Reporter 39, 10640-10641.

May, R.M., Levin, S.A., Sugihara, G., 2008. Ecology for bankers. Nature 451, 893-895.

Moir, W.H., Block, W.M., 2001. Adaptive management on public lands in the United States: commitment or rhetoric? Environmental Management 28, 141-148.

(2005). National Cable and Telecommunication Ass'n v. Brand X Internet Service. U.S. Supreme Court.

Nie, M., 2008. The underappreciated role of regulatory enforcement in natural resource conservation. Policy Sciences 41, 139-164.

Norton, B.G., 2005. Sustainability: a Philosophy of Adaptive Ecosystem Management. University of Chicago Press, Chicago.

Nystrom, M., 2006. Redundancy and response diversity of functional groups: implications for the resilience of coral reefs. Ambio 35, 30-35.

Peterson, G.D., Allen, C.R., Holling, C.S., 1998. Ecological Resilience, Biodiversity and Scale Ecosystems, 1, pp. 6-18

Ruhl, J.B., Kraft, S.E., Lant, C.L., 2007. The Law and Policy of Ecosystem Services. Island Press, Washington, D.C.

Ruhl, J.B., 2005a. The Disconnect Between Environmental Assessment and Adaptive Management Trends, 36, pp. 6.

Ruhl, J.B., 2005b. Regulation by adaptive management - is it possible? Minnesota Journal of Law, Science and Technology 7, 21-57.

Ruhl, J.B., 2008a. Adaptive Management for Natural Resources - Inevitable, Impossible, or Both?, vol. 54. Rocky Mountain Law Institute. $\S 11.01-06$.

Ruhl, J.B., 2008b. A square peg in a round hole. Environmental Forum 25, 35. 35.

Simon, H.A., 1973. The organization of complex systems. In: Pattee, H.H. (Ed.), Hierarchy Theory. G. Braziller, New York, pp. 3-27.

Stryker's Bay Neighborhood Council, Inc. v. Karlen. (1980). U.S. Supreme Court.

Thrower, J., 2006. Adaptive management and NEPA: how a nonequilibrium view of ecosystems mandates flexible regulation. Ecology Law Quarterly 33, 871-895.

U.S. Army Corps, 2002. Guidance on Compensatory Mitigation Projects for Aquatic Resource Impacts under the Corps Regulatory Program Pursuant to Section 404 of the Clean Water Act and Section 10 of the Rivers and Harbors Act of 1899.

U.S. Department of Interior, 2008. Adaptive Management: The U.S. Department of Interior Technical Guide.

U.S. Forest Service, 2009. Notice of Intent to Prepare and Environmental Impact Statement. In Federal Register, pp. 67165-67101.

Virah-Sawmy, M., Gillson, L., Willis, K.J., 2009. How does spatial heterogeneity influence resilience to climatic changes? Ecological dynamics in southeast Madagascar. Ecological Monographs 79, 557-574.

Walters, C.J., Holling, C.S., 1990. Large-scale management experiments and learning by doing. Ecology 71, 2060-2068.

Walters, C.J., 2002. Adaptive Management of Renewable Resources. The Blackburn Press, Caldwell, New Jersey.

Wilhere, G.F., 2009. Three paradoxes of habitat conservation plans. Environmental Management 44, 1089-1098.

Williams, B.K., Szaro, R.C., Shapiro, C.D., 2007. Adaptive Management: The U.S. Department of the Interior Technical Guide. U.S. Department of the Interior, Washington, D.C., USA. 